\title{
El desmontaje de creencias bien fundadas: elementos para una sociología de la historieta
}

ABSTRACT: We present the basic concepts for a comic book sociology that may dwell upon its history as field. Our theoretical framework, following Pierre Bourdieu, requires that we construct as field the studding of positions and relations that are formed around comics, the habitus of the social agents that occupy such positions, as well as practices that define the configuration of the field, its rules, its functioning across time. To understand the various degrees of autonomydependence in the production, as well as also the competition between the new and the old in the historical processes that can transform the field, it is the key to study the relationships between the field of comics and others fields, especially capitalist business and the professional evolution of the agents involved (publishers, scriptwriters, draftsmen, readers).

Keywords: comics, sociological theory, field, habitus, history.

RESUMEN: Presentamos los conceptos básicos para una sociología de la historieta que indague su historia como campo. La perspectiva teórica, orientada por la de Pierre Bourdieu, requiere construir como campo el conjunto de posiciones y relaciones que se traman alrededor de la historieta, los habitus de los agentes sociales que ocupan esas posiciones, como sus prácticas que definen la configuración del campo, sus normas, su funcionamiento, a través del tiempo. Es clave estudiar las relaciones entre el campo de la historieta y otros campos, en particular con el empresarial capitalista, como también las trayectorias de los agentes (editores, guionistas, dibujantes, lectores), para comprender los grados de autonomía-dependencia en la producción, y la competencia entre lo nuevo y lo viejo en los procesos temporales de transformación del campo.

Palabras clave: historieta, teoría sociológica, campo, habitus, historia. 


\section{Introducción}

Las prácticas de editores, productores, lectores, etc. -agentes sociales- que editan, realizan o leen historietas tienden a estar orientadas por una illusio, una libido socializada, construida sobre el desarrollo de un deseo (que puede mutar en el tiempo, en particular por las relaciones con otros deseos o necesidades) por esa específica forma de narrar -secuencialmente con viñetas, textos e imágenes (Groesteen, 2009) - que denominamos historieta. Esa illusio se constituye temporalmente a partir de un posicionamiento en el campo de la historieta, condicionada por las relaciones con otras posiciones ocupadas por otros agentes y con otras posiciones ocupadas por el mismo agente en la sociedad. Ocupar una posición implica detentar capitales que funcionan como fuerzas y -tanto para editores, productores, lectores, etc.- el inevitable trazado de unas trayectorias sobre el transcurso del tiempo y en relación a situaciones históricas específicas, trayectoria durante la cual van desarrollando disposiciones o habitus -estructuras internas subjetivas- que orientan a que las prácticas sean realizadas más de una forma que de otra. El campo es un espacio en el cual, en relación a capitales que allí se juegan, quienes ocupan posiciones en él compiten, luchan, permanentemente, en un entramado relacional donde unos agentes están arriba, otros en el medio y otros abajo (esta estratificación puede, y debe, complejizarse de acuerdo a las necesidades de las investigaciones particulares y sus objetivos). El campo, construcción conceptual y por lo tanto herramienta para la indagación, que denominamos campo de la historieta, se relaciona con otros campos, como el económico o empresarial capitalista, que históricamente han tendido a dominarlo; aunque se trata de un espacio con una geografía social variable en complejidad, que se divide en regiones, la mayoría de las cuales son tendencialmente dominadas, mientras otras son tendencialmente autónomas (u otras variantes intermedias).

Es probable que este primer párrafo pueda provocar algunos interrogantes y cuestionamientos que variarán según las posiciones, trayectorias y disposiciones de quienes lo lean:

«Se supone que se trata de un artículo sobre historietas pero parece distante de las mismas. Utiliza un lenguaje no usual en los estudios» (salvo para aquellos familiarizados con la sociología, particularmente con la de Pierre Bourdieu [1988, 1995], y con las indagaciones específicas existentes desde esta perspectiva). Los estudios sobre historietas se han desarrollado básicamente desde perspectivas semióticas o relacionadas con las teorías literarias (narratología, teoría de la enunciación, etc.), orientaciones que han realizado los aportes más significativos para la compresión de la historieta. Pero el grueso de «los textos sobre historietas», particularmente los libros que más han circulado, adolecen de unos grados diversos y sorprendentes de ateoricidad. Son crónicas, con una que 
otra reflexión, en los cuales suele predominar la reconstrucción enumerativa de acontecimientos, obras y autores.

«Se utiliza una terminología y unos planteamientos innecesariamente complicados»». No se puede dar cuenta en forma simple y universalmente sobre un objeto de estudio que es complejo y, aunque en las universidades e instituciones de investigación haya existido una tendencia a considerar a la historieta como un objeto no demasiado digno de estudio - a diferencia de la literatura, por ejemplo-, la historieta constituye un campo de investigación tan complejo como cualquier otro de los que abordan las ciencias sociales e implican un entramado de relaciones humanas sobre condicionamientos, deseos y prácticas.

«Se habla de historietas y no de cómics que es lo habitual». Lo «habitual» puede ser quedar atrapados por el objeto y es producto del desarrollo de un proceso de imposición cultural que ha llevado a que en la mayoría de los países las denominaciones originales (tebeos en España, por ejemplo) haya sido reemplazada por la estadounidense. ${ }^{1}$ Hemos optado por el termino historietas que se afianzara en el siglo pasado en Argentina -donde convive, en particular desde los noventa, con la de cómic-, aunque ello también podría implicar quedar atrapados, por lo cual hemos necesitado trabajar fuertemente en objetivar no solo el objeto sino también al sujeto objetivante (Gutiérrez, 2002).

«No se hace referencia a historietas y momentos teóricos concretos, es pura e inútil abstracción». En cuanto a la crítica a la «abstracción» no hace falta responderla en una publicación científica. Y si la perspectiva en que estamos es centralmente teórica deviene de investigaciones empíricas sobre el campo de la historieta argentina -consideramos que la teoría no puede desarrollarse sino es sobre la investigación empírica-. Dada esa especificidad de un campo con unos desarrollos particulares, que el presente artículo va a ser publicado en España, el escaso espacio disponible - entre otras razones- optamos por presentar los elementos teóricos más relevantes, con algunos anclajes empíricos escuetos, que venimos aplicando hace algunos años y que ha dado lugar a publicaciones, ponencias y proyectos en la Universidad Nacional de Córdoba, Argentina.

La lista podría extenderse pero ya resulta suficiente y nos termina de introducir a la escueta presentación de una perspectiva sociológica respecto de la cual se desarrollarán los conceptos básicos, como las relaciones entre esos conceptos, con miras a construir una historia sociológica del campo de la historieta y de los habitus y prácticas de los agentes que forman parte de él. Perspectiva sociológica que no se pretende como la única, aunque si como apropiada, dado que

1. Japón conserva la denominación propia: manga. Lo cual tiene que ver con un modo de producción que tiene una fuerte identidad, diversidad, e importante mercado interno. 
existe más de una sociología desde la cual sería posible abordar nuestro objeto de estudio. El párrafo inicial incluyó apretadamente una síntesis que supone para su comprensión, pero no solo, una noción básica de la teoría de Pierre Bourdieu (1988, 1995). También habría que señalar que esto es un artículo y no un libro, por lo tanto, el desarrollo de la teoría, y su relación con la empiria, es limitada e incompleta.

Al final del texto, y previamente a la bibliografía, incluimos un gráfico, simplemente a modo de ejemplo sobre cómo se podría construir un mapa del campo de la historieta para alguna situación específica, más allá de que la mayoría de sus elementos pueden estar presentes en cualquier mapa.

\section{Desarrollo}

Debemos tener en cuenta que la historieta nace y transcurre, como tendencia estructural, como un campo dominado por el campo económico, en particular por el campo empresarial capitalista, y que a partir de esas condiciones se construyen las disposiciones (estructuras internas subjetivas) (Gutiérrez, 2002) de los productores culturales reales (guionistas y dibujantes, que pueden ser una sola persona), habitus que a su vez orientan las prácticas que construyen los campos.

Campos, habitus y prácticas aparecen inmediatamente como conceptos centrales a ser tenidos en cuenta al proponer una historia sociológica, lo cual impone la tarea de historizarlos. Campos y habitus en cuanto estados de los primeros y trayectoria de los agentes sociales que han interiorizado esas disposiciones que componen el habitus de cada uno de ellos; prácticas en cuanto son las que concretamente reproducen, promueven o realizan el cambio. Campos, habitus y prácticas no solo se construyen en el tiempo, lo hacen en situaciones históricas específicas (Weber, 2011).

Bourdieu considera a los campos, que en su conjunto constituyen el espacio social general (el nivel macrosocial de indagación), como estructuras externas objetivas (Gutiérrez, 2002) en los cuales los agentes sociales -individuales y colectivos- ocupan posiciones y compiten entre sí por un capital específico que, para él, define la existencia del campo. Plantea que podemos construir un campo en cuanto detectemos un capital particular en juego e interesados en disputarlo. En relación a nuestro propósito consideramos necesario realizar alguna modificación a ese planteo. En cuanto los campos se solapan entre sí, y unos campos tienden a dominar a otros, la distinción entre capitales específicos se vuelve lábil, especialmente con la expansión en las últimas décadas de la industria cultural y la última expansión capitalista. Ya hemos planteado que el campo de la historieta es un campo que ha estado y sigue estando, como una tendencia estructural, dominado por el campo económico. La historieta pertenece también al campo de la producción cultural y este campo, en cuanto industria cultural, sigue la misma tendencia. Consideramos que para definir un campo hay que distinguir lo que se produce y circula en el 
mismo y que ello no necesariamente constituye un capital distintivo, específico y particular (recordemos que Bourdieu usa tal concepto en un sentido amplio, que puede incluir desde el capital monetario al capital salvación de las almas) (1988), pudiendo ser simplemente un elemento, una actividad, de múltiples dimensiones (historieta), alrededor de la cual se entrecruzan las prácticas de numerosos agentes, para los cuales la illusio, el deseo base de la creencia que lleva a jugar un juego, puede ser distinto para distintos agentes, como puede variar durante la trayectoria de agentes en particular -ya sean individuales o colectivos, incluyendo las empresas-. En apariencia todos juegan el mismo juego, comparten la misma illusio, posicionalmente orientada, alrededor de un capital propio del campo (hacer historietas, para los productores culturales reales; editarlas, para los editores; leerlas, para los consumidores). Pero el capital en juego y el interés en hacer historietas -tomemos el caso de guionistas y dibujantes- puede funcionar por distintas creencias y solo en apariencia el movimiento puede parecer el mismo. Si efectivamente nos encontramos ante un campo dominado por el campo empresarial capitalista, el objetivo de los agentes es el capital económico -aumentar o al menos mantener el capital económico que poseen- prevaleciente en el espacio social macro. Los lectores, los consumidores, dominados en este mercado, lo son en esta lógica en tanto son quienes demandan historietas para leer (así como los fieles son los dominados en el campo de la religión católica en cuando demandan el capital salvación de las almas que puede ser otorgado por la iglesia, dominante).

El campo también puede estar dominado por otros campos. En España, durante el extenso periodo de la dictadura de Franco, estuvo dominando por la política del campo del Estado Gobierno. La dominación, de peso variable, también puede provenir del campo de la política sin necesidad de que sea un control directo del Estado Gobierno, en cuanto -verbigracia- es impuesta por normas que los editores imponen -y se imponen- a la producción, desde una incierta censura a una censura institucionalizada como la del Comics Code Authority en Estados Unidos de Norteamérica (Duveau, 1975: 37/38).

Entonces la illusio, y cómo se juega el juego en un mismo campo, pueden ser diversos y relacionarse a distintos capitales. Existen productores culturales reales interesados en producir obra - por el interés en la obra misma- lo cual supone un deseo que lo convierte en necesidad, homólogo, en su funcionamiento y posibles consecuencias, al arte puro, y sigue perteneciendo al campo más allá del interés económico. ${ }^{2}$ Guionistas y dibujantes pueden, y lo hacen algunos, no

2. Podríamos pensar en una apuesta que prescinde de aquella otra que supone la historieta que se hace para llegar al gran público, para obtener una paga, o que plantea que se debe facilitar la comprensión al lector, lo que redundaría en mayores ventas. Tendencialmente hay más posibilidades de que estas prácticas aparezcan cuando aumentan las regiones de autonomía; por ejemplo, con la digitalización e Internet que posibilitan nuevos formatos y modos de producción. 
publicar sus obras, ponerlas -gratuitamente- a disposición de posibles lectores en un sitio o en blog de internet, en una red social como Facebook, en forma de e-book que puede descargarse por Internet, ${ }^{3}$ con o sin conciencia reflexiva de que la inversión desinteresada puede brindar intereses en el futuro (o no). Los intereses que los mueven pueden ser múltiples, incluso para los editores. Claro que una de las condiciones de posibilidad de la existencia de un productor cultural real autónomo es tener ingresos monetarios en otras actividades o rentas (como sucedió con Gustave Flaubert, campo de la literatura francesa, siglo XIX):

La propensión a orientarse hacia las posiciones más arriesgadas, y sobre todo la capacidad de ocuparlas de forma duradera, prescindiendo de todo beneficio económico a corto plazo, parecen depender en gran medida de la posesión de un capital económico y simbólico importante. Primero porque el capital económico garantiza las condiciones de libertad respecto a las necesidades económicas, ya que la renta constituye sin duda, uno de los mejores sustitutos de la venta (1995: 387).

Muy distinta es la illusio de aquel productor cultural real para quien, desde el comienzo, o en algún momento de su trayectoria, la libido puesta en juego busca la profesionalización, por lo tanto trabajo rentado. Ese productor cultural real, reflexivamente o no, está objetivamente aceptando, convalidando, y por tanto reforzando, la dominación del campo económico sobre el campo de la historieta. Se podría decir que se condenan al artesanado, a condenar el arte y a la defensa del mercado. Podemos verlo, por ejemplo, en declaraciones de Hugo Pratt, quien, sin embargo, fuera un innovador de la historieta como dibujante en la historieta argentina de los cincuenta, pero especialmente -como guionista y dibujante al mismo tiempo- a partir del comienzo de la publicación de El Corto Maltés en Europa desde 1967 (Cáceres, 2011: 11):

[A la historieta contemporánea] La encuentro arrogante, pretenciosa y desordenada. Los dibujantes se olvidan de que son artesanos y pretenden ostentar sus virtudes gráficas: se sienten Rafael; y los guionistas, Dante. Después las revistas se hunden y desaparecen porque no agradan al público. El guión tiene que contar algo en forma comprensible, y los dibujos deben ser sencillos, simples, eficaces para que el diálogo y la narración funcionen. Si no se obtienen cuadros como los de Harold Foster,

3. Aquí aparece una cuestión que también es clave y no podremos desarrollar más que complementariamente en este artículo: las innumerables modificaciones, y apertura a posibilidades antes inéditas, que implica la informatización y la aparición de Internet, que afectan a campos, regiones, habitus, prácticas, relaciones entre posiciones y, que especialmente, contribuye al crecimiento de regiones de autonomía al modificar los criterios, agentes y mecanismo de consagración. 
ante los cuales el lector se detenía a contemplar soberbios frescos acerca del mundo medieval y pasaba por alto el relato.

¿Qué ocurre cuando se produce un cataclismo en campo? ¿Cuando el mercado desaparece, como ocurrió en Argentina a principios del nuevo milenio? Diez años después existe un mercado interno minúsculo, fragmentado y con raras posibilidades de obtener ganancias con historietas argentinas -tanto para editores, como para productores culturales reales- salvo unas pocas excepciones (publicar en diarios, revistas infantiles... o trabajar para el exterior). Federico Reggiani considera, irónicamente, en una especie de manifiesto autonómico (2012: 2):

Lo más estimulante que estos tiempos menesterosos tienen para ofrecerle a la historieta argentina es que, por motivos diversos y a la fuerza, toda la historieta se convirtió en experimental, y los historietistas se convirtieron en los ratones de su propio laboratorio. Acá no importa si el modelo es un folletín del siglo XIX o un poema de Vallejo, Velázquez o Mondrian. Importa que a los historietistas no les queda otra opción que hacer de la necesidad virtud, y hacer historietas sin saber del todo qué les espera al final del camino. No solo qué resultado va a obtener, «la obra», sino qué les espera como personas [...] [Concluye, luego de referirse a las dos historietas más innovadoras de 2011, editadas por un autoeditor y con derechos de autor cubiertos con libros, una especie de trueque] Historietas que no se parecen a nada, que serán leídas por lectores que no sabemos a qué se parecen. Es un camino tan bueno como cualquier otro, pero que parece más interesante para recorrer.

La crisis que vive la Unión Europea en 2012 aún no ha provocado un cataclismo, pero la recesión amenaza el campo de la historieta comercial (otra forma de decir «dominado por el campo del empresariado capitalista»).

La libido puede funcionar en múltiples direcciones y poner en juego el deseo de hacer obra y al mismo tiempo el deseo de obtener dinero por la obra, o hacer obra autónoma para una región del campo y otras obras dependientes de los mercados a los cuales se pretende vender. Asimismo, y en asociación a las disposiciones construidas e interiorizadas en el espacio social general y en otros campos: «[...] las mismas disposiciones pueden llevar a tomas de posiciones estéticas o políticas muy diferentes según el estado del campo respecto al cual tienen que determinarse» (Bourdieu, 1995: 393). 
Dado que la producción intelectual sobre cualquier campo de la producción cultural suele ser catalogada, por parte de historietistas y editores, como injurias o falsedades de alguien que no pertenece al campo, ${ }^{4}$ no está de más aclarar que no valoramos aquí las disposiciones y prácticas de los agentes como «buenas»o como «malas», simplemente señalamos, ahora teóricamente, lo que muestran las indagaciones. Apunta P. Bourdieu (1995: 361):

La ignorancia de la problemática específica que históricamente se ha constituido en el campo y respecto del cual las soluciones presentadas por el especialista adquieren su sentido lleva a considerar los análisis científicos como respuestas a preguntas de sentido común, a interrogaciones prácticas, éticas o políticas, es decir como opiniones, como ataques las más de las veces (debido al efecto de revelación que producen).

La cuestión anterior es particularmente visible cuando se producen modificaciones estructurales en los campos, cataclismos pocos habituales en el de la historieta, como el citado en Argentina. En estas situaciones se visibiliza y acentúa la reflexividad en los agentes del campo y las discusiones entre los mismos. Para entender tal situación deberemos considerar las luchas entre lo nuevo y lo viejo. Según Bourdieu «hacer época significa indisolublemente hacer existir una nueva posición más allá de las posiciones establecidas, por delante de estas posiciones, en vanguardia, e, introduciendo la diferencia, producir el tiempo» (Bourdieu, 1995: 237).

Al estudiar la trayectoria del campo se estudian sus estados y por lo tanto los procesos de envejecimiento. Es la lucha a través de la cual se hace la historia del campo, se temporaliza (Bourdieu, 1995: 237):

El envejecimiento de los autores, de las obras, o de las escuelas es algo muy distinto del producto de un deslizamiento mecánico hacia el pasado: se engendra en el combate entre aquellos que hicieron época y que luchan por seguir durando, y aquellos que no pueden hacer época sin remitir al pasado [...].

Para referirnos a esas luchas por los posicionamientos haremos referencias empíricas a la historia del campo de la historieta argentina, tomando como excusa que el autor clave del proceso al que nos referimos ha sido ampliamente publicado en España, como también en Francia e Italia.

4. Cuando al existir un campo de investigación sobre este objeto particular dicho campo se solapa y se engrampa al de la historieta, posicionando a los investigadores en él mismo y pudiendo producir efectos aunque solo sea por el reconocimiento como objeto digno de estudio (en contra de las corrientes que han considerado a la historieta como un objeto que no merecía ser considerado en las universidades, por ejemplo). 
Hasta los noventa, la historieta argentina funciona como una industria cultural, salvo las excepciones de la denominada primavera de los fanzines con la vuelta de la democracia (Barreiro, 1998). Dentro de esas condiciones de producción se realizan visibles operaciones de modificación de posiciones -por lo tanto, de la aparición de nacimientos y envejecimientos, y de normas sobre la forma correcta de hacer historietas-. El caso más notable es el de Carlos Trillo, al que acompaña inicialmente Guillermo Saccomanno, que durante los setenta realizan por entregas una Historia de la Historieta en la revista Tit-Bits, que va a ser recopilada en formato libro por Ediciones Record, la editorial comercial en la cual trabajaban, en 1980, como La historia de la historieta argentina y que se va a convertir en la historia oficial (von Sprecher y Pestano, 2010). Señala Lucas Berone (2010: 1):

En su valioso libro sobre La historia de la historieta argentina, Carlos Trillo y Guillermo Saccomanno lograron imponer un relato modélico del desarrollo histórico del campo de la historieta en nuestro país tan interesante y eficaz, que aún hoy no ha sido puesto en tela de juicio ni ha podido ser reemplazado por otro modelo.

Trillo y Saccomanno realizan una operación que les reditúa beneficios en tanto son autores y críticos al mismo tiempo. Logran hacerse un nombre conocido y reconocido que les otorga poder de consagrar. Sus firmas consagran sus propias historietas (efecto «de firma») y pueden consagrar autores o re-consagrar, como lo hacen con Héctor Germán Oesterheld, a quien utilizaron para consagrarse. Además de legitimar sus firmas como guionistas y como críticos, se erigen en constructores de la historia oficial de la historieta argentina. Trabajando desde una empresa comercial, Ediciones Record, lo que los va a llevar al éxito comercial, y oponiéndose a «lo comercial», nominando como tal a Editorial Columba, construyen una posición en la cual el capital simbólico se reconvierte en capital económico. Considera Sebastian Gago (Documento interno de trabajo Equipo de Investigación Estudios y Crítica de la Historieta, Universidad Nacional de Córdoba, 2010):

Esto es lo que hace a Trillo una especie de banquero simbólico con un fuerte poder de mediación sobre la circulación -y el consumo y producción- de mercancías; o sea, siempre y cuando hablemos de producción, circulación y consumo como momentos separados solo analíticamente.

No habría que perder de vista que, además, particularmente Carlos Trillo va a hacer época, va a posicionarse por delante, también, en la forma -que constituye normas - de guionar/narrar historietas predominantes hasta el momento de la aparición de sus historietas en Ediciones Record, al usar un tipo de narración 
que prescinde casi siempre de los textos de apoyo que proliferaban en Editorial Columba. Trillo adopta, y propone, una nueva norma que venía a plantear que no se debía decir con textos de apoyo aquello que se podía decir con imágenes, y que, en todo caso lo que era remitido por necesidades narrativas a los textos de apoyo podía serlo a los globos de parlamentos o pensamiento, aunque ello supusiera una contradicción parcial con la forma de narrar de Oesterheld, a quien recurre para re-consagrarlo y, en esa misma operación, consagrarse.

El caso de Carlos Trillo es importante en tanto sigue hasta el momento de su muerte en mayo 2011, realizando operaciones para mantenerse entre los nuevos, entre la vanguardia, mostrando competencia para ajustarse y reubicarse ante profundos cambios del campo, ante los cuales buena parte de sus colegas quedan desajustados o trabajando exclusivamente para el mercado externo (Italia, principalmente), para el cual Trillo también trabaja como un guionista reconocido y consagrado.

Los párrafos anteriores introdujeron una cuestión central a todo campo: los criterios, mecanismos y agentes de consagración. Son aquellos agentes que realizan una valoración, casi siempre en lucha con otras, que suponen un reconocimiento que puede ser tanto de las historietas como de los editores (como de los propios críticos que también juegan el juego de unir o romper filas). Este reconocimiento constituye un capital simbólico, que es un capital adjetivo que se agrega a los otros capitales -sustantivos-, y si bien normalmente se considera al capital simbólico en cuanto reconocimiento positivo también puede tratarse de un capital simbólico denegatorio, por ejemplo, si se afirmara que las historietas de El Guerrero del Antifaz son arcaicas (Williams, 1982). Según el momento histórico, los agentes de consagración pueden ser los editores, los productores culturales reales (los colegas), los premios que otorgan instituciones y asociaciones (el Premio Will Eisner o el Yellow Kid), los críticos (que publican en papel o en Internet), los lectores, etc. Los agentes privilegiados de consagración y los criterios de consagración son indicadores claves para determinar el grado de dependencia-autonomía del campo y sus regiones. Si el nivel de ventas es el criterio central, tenemos un indicador de que el campo está dominado por el campo empresarial capitalista, la consagración es heterónoma, proviene de otro campo. También es heterónoma cuando desde el campo del arte se consagran historietas como obras de arte, como ocurriera, por ejemplo, en la Muestra del Louvre de 1967 y con la Bienal Internacional de Buenos Aires de 1968. Cuando se denomina novela gráfica (en su uso actual) a la historieta se está recurriendo a una etiqueta que produce varios sentidos: se utiliza una denominación que proviene del campo de la literatura (una de las artes clásicas) como gesto heterónomo de reconocimiento, allodoxia por lo tanto, gesto externo de préstamo de capital simbólico (reconocimiento como arte) y al mismo tiempo se contribuye al campo empresarial que puede vender esas historietas en lugares 
que no son aquellos en los cuales está ha sido vendida habitualmente, con unas ediciones que tienen unas características que no son las que han prevalecido históricamente y que las acercan en formato y precios a los libros que reproducen obras de arte. El movimiento heterónimo de reconocimiento puede provenir de los agentes del propio campo de la historieta: Alan Moore -célebre guionista británico, consagrado en el mercado estadounidense-, que repudia el uso del término novela gráfica y ha modificado las normas del campo sobre los superhéroes con Watchmen, sin embargo se designa a sí mismo como un mago y a la magia como un arte y en consecuencia se auto designa como artista. En cambio aquellos productores culturales reales que se consideran profesionales tienden a rechazar el reconocimiento de la historieta como arte. Se puede hipotetizar que este rechazo, con frecuencia colérico, deviene de que reconocer la historieta como arte implica cambiar la posición (el oficio) de guionistas y dibujantes y, por lo tanto, las normas del campo y la forma misma de vivir.

Pilar Heredia ha explicado algunas de las cuestiones que ponen en movimiento el solapamiento, las relaciones, entre el campo del arte y el campo de la historieta, en un texto donde hace hablar a ciertos críticos locales, en una situación ficticia, a partir de sus propios textos, así en uno de sus parlamento el personaje Reggiani de este ensayo afirma (Heredia, 2012: 2/3):

Y tiene razón, mi amigo, es lo que he denominado estantificación, un meticuloso procedimiento autorizado que, con un formato en el tamaño justo y un buen prólogo legitimador, lleva a cualquier obra directo a los estantes de la biblioteca del letrado. Fíjese cómo los prólogos que acompañan estas historietas siempre hablan de recuerdos del pasado (generalmente ligados a la infancia), como si lo que se estuviese a punto de leer fuera digno de leerse porque ya ha sido leído por alguien que autoriza su lectura -el crítico de la caja se quedó un rato saboreando el trabalenguas que había producido la teorización-. A propósito, usted me recuerda a un Juan que prologó un libro como el que tiene en la mano.

Aclarando la autora (2012: 2) que:

Este Reggiani de la caja de críticos debajo de la sección de películas truchas ya había expuesto su Teoría de la Estantificación en «Quisiera ser literatura: el prólogo como recurso de legitimación en la edición de libros de historieta en Argentina. El caso de la Biblioteca Clarín de la Historieta».

Si los criterios de consagración son internos al campo, valoración de las obras mismas sin importar su nivel de ventas, más allá de su formato, de la vía de publicación y con una positivación de la innovación, y los agentes de consagración pertenecen al campo, tenemos fuertes indicadores de que nos encontramos, 
al menos, ante una región autónoma del campo o un campo con un extenso espacio de autonomía. Hay que tener en cuenta (Bourdieu, 1995: 214) que:

[...] los campos de producción cultural se organizan según un principio de diferenciación que no es más que la distancia objetiva y subjetiva de las empresas de producción cultural respecto al mercado y a la demanda expresada o tácita, ya que las estrategias de los productores [y de los agentes de consagración] se reparten entre dos límites que, de hecho no se alcanzan nunca, la subordinación total y cínica a la demanda y la independencia absoluta respecto al mercado y sus exigencias».

La diferenciación es parte de los procesos de construcción del gusto y por lo tanto de la distinción, uno de los mecanismos más sutiles de la desigualdad y de la dominación social tanto en el espacio social general como en los campos.

Con la masificación de Internet gran parte de las competencias por la consagración se ha desplazado a los espacios digitales: las disputas por el valor otorgado a la historieta en general o a historietas en particular ha entrado en un estado de elevada virulencia, intercambio y discusión, en cuanto las luchas por el reconocimiento se han instalado en páginas web, en blogs, en las cuales pueden intervenir todos los que ocupan posiciones en el campo (o no) y de hecho lo hacen (ver los comentarios a Reggiani, 2012).

Parece pertinente considerar ahora el concepto de regiones de los campos. No equiparamos al concepto con el de sub-campos de Bourdieu -más allá de algunas homologías- y proponemos considerar la geografía social en que consisten los campos dividida en regiones que se diferencian por su grado de dominación (por otros campos) o autonomía de los mismos, aunque nunca existe una heteronomía absoluta ni una autonomía absoluta. Las regiones con mayor autonomía tienden a desarrollar unos modos de producción en los cuales preponderan, aun como necesidad convertida en virtud, el hacer obra. Estos modos de producción se multiplican y complejizan con la informatización e Internet. Las regiones con mayor dependencia del mercado, del campo empresarial capitalista, tienden a desarrollar modos de producción más estereotipados y tradicionales. De cualquier manera, en las teóricamente infinitas y variables regiones, con los posibles traslados y viajes de los agentes entre las mismas, cada modo de producción supone normas y condiciones de posibilidad, y relaciones de producción distintas y que se modifican en mayor o menor grado con el transcurso del tiempo. Siendo en las regiones dominadas donde las modificaciones son más lentas. Volvamos a España y recordemos que la muerte de Franco fue el punto clave para la proliferación de nuevas publicaciones, editores, autores, lectores, a pesar de que un lento proceso de innovación se había ido produciendo en esa región dominada doblemente: por el campo político y por el campo empresarial. Quizás donde esto se puede ver 
con más precisión es en una historieta de Paco Roca, El Invierno del Dibujante (2010), que narra cómo -a fines de los cincuenta- un grupo de dibujantes de Editorial Bruguera (la editorial de mayor importancia económica durante mucho tiempo) llevó adelante la revista Tío Vivo, buscando la independencia de aquella gran editorial, convirtiendo productores culturales reales en editores (proceso que ha sido bastante frecuente en Argentina) y fracasó.

La competencia por la legitimidad, obviamente, varía fuertemente en criterios, mecanismos y agentes de consagración, en los procesos de construcción de lo nuevo y lo viejo, según las regiones de los campos que, obviamente, no son homogéneas. Asimismo varían la génesis de los habitus de los agentes y sus trayectorias. Puede ser frecuente que quienes se posicionen inicialmente en regiones autónomas terminen emigrando a regiones dominadas, movilidad tendencialmente sustentada por el capital conformado en las más autónomas (el interés que con el tiempo puede brindar el desinterés inicial), con la implicancia de poder seguir sosteniendo las formas y los criterios de producción conformados previamente. En términos de Williams, una producción alternativa se convierte en innovación (Williams, 1980, 1982).

\section{Cierre}

Consideramos que las conclusiones a este artículo ya fueron realizadas en la marcha forzada que impuso el extenso primer párrafo. Aconsejamos retornar y volver a leerlo.

Hemos presentado no una alternativa a la semiótica, o a otras líneas -emparentadas con la teoría literaria- desde las cuales se ha estudiado y se estudian las historietas, sino otra perspectiva: una sociología de la historia de la historieta, que aplicada empíricamente ya está colaborando a explicar el campo.

Finalmente, una referencia al título: «Desmontaje de creencias bien fundadas» (juego de palabras a partir de otros juegos de palabras de Mallarmé y de Durkheim). Las creencias de quienes compiten, en el campo de la historieta, son el resultado de un proceso, de unas condiciones de producción que les ha impuesto la historia, que lleva a que esas creencias - construidas en relación a posiciones e intereses- sean consideradas como la naturaleza misma de las cosas (con pocas excepciones, las cuales aumentan en las regiones más autónomas). La reflexión racional sobre esas formas de pensar, que no son naturales sino socialmente construidas, contribuye a la concientización de los agentes sobre los juegos que juegan y a comprender sus creencias y prácticas. Por lo tanto, a su libertad. 


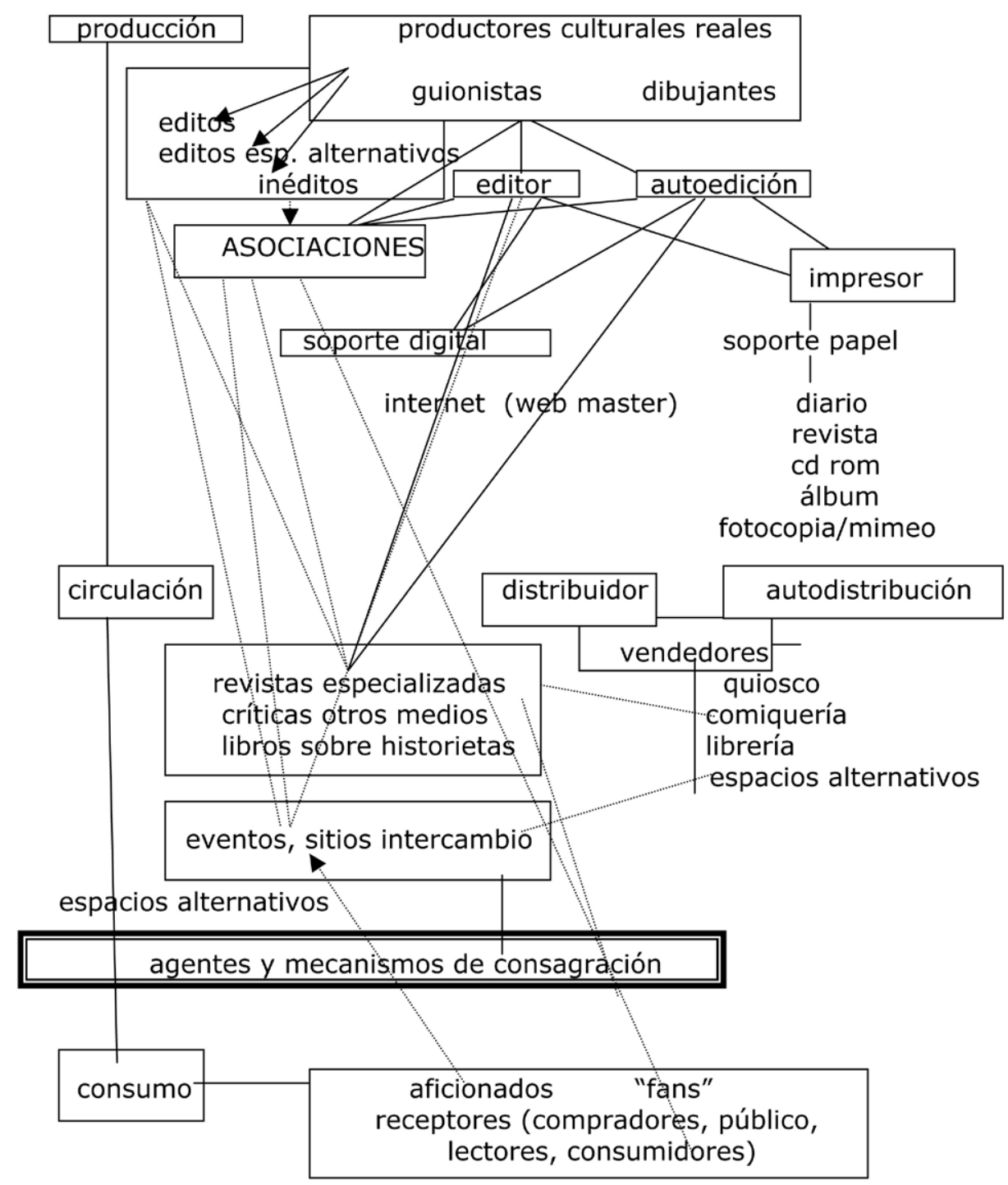

\section{Gráfico}

Campo historieta realista argentina 


\section{Referencias bibliográficas}

AguiRre, M. (2007): «El canon Mc Millan», en www.historietasreales.wordpress.com

Barreiro, R. (1998): Historia de los fanzines de historieta en Argentina, Buenos Aires, Libros enRed.com.

BARreto, M. (2009): «Viñetas desarraigadas. La hégira de historietistas latinoamericanos a otros mercados: el caso de Argentina», La Habana, Revista Latinoamericana de Estudios sobre la Historieta, 2(6): 93-104.

Berone, L. (2010): «Campo literario y campo de la historieta en Argentina. Notas para un análisis en fase», Ponencia presentada en Viñetas Serias. Universidad Nacional de Buenos Aires.

- (2011): La fundación del discurso sobre la historieta en Argentina: de la «operación Masotta» a un campo en dispersión, Córdoba, Colección Estudios y Crítica de la Historieta Argentina. Escuela de Ciencias de la Información, Universidad Nacional de Córdoba.

Bourdieu, P. (1988): La distinción. Criterios y bases sociales del gusto, Madrid, Taurus.

- (1995): Las reglas del arte. Génesis y estructura del campo literario. Anagrama. Barcelona.

CaCeres, G. (1998): Charlando con Superman, Buenos Aires, Editorial Fraterna, reproducida y consultada en línea:

http://laduendes.blogspot.com.ar/2011/10/entrevista-hugo-pratt-segundaparte.htm

Caraballo, L. (2010): «Historieta Argentina: del Fanzine al Weblog», La Plata, en línea: http://www.fba.unlp.edu.ar/news/SCYTEC/PDF/CARABALLO\%202.pdf

Сома, J. (1978): Los cómics un arte del siglo XX, Madrid, Guadarrama.

- (1979): Del gato Félix al gato Fritz, Barcelona, Gustavo Gili.

- (1981): Y nos fuimos a hacer viñetas, Madrid, Penthalon.

Duveau, M. (1975): Comics USA, París, Albin Michel.

Fenty, S.; T. Houp; L. TaYlor (2004): «Webcomics: the Influence and Continuation of the Comic Revolution», ImageTexT: Interdisciplinary Comics Studies, 1(2) [en línea: http://www.english.ufl.edu/imagetext/archives/v1_2/ group/]

GaGo, S. (2009): «El conocimiento, capital definitorio del campo del poder. Su aplicación en El Eternauta», Revista Tebeosfera Segunda Epoca, 2 [en línea: http://www.tebeosfera.com/portada.php]

- (2010): «Los estudios de recepción, una necesidad del campo de la historieta de Argentina». Córdoba, Grupo de Investigación Estudios y Crítica de la Historieta, inédito. 
Groesteen, T. (2007): The System of Comics, Jackson, University Press of Mississippi.

- (2009): «The Impossible Definition» en HeER, J.; K. WorCester (eds.): $A$ Comic Studies Reader, Jackson, University Press of Mississippi.

GubERN, R. (1973): Literatura de la imagen, Salvat. Barcelona.

- (1979): El lenguaje de los cómics, Barcelona, Península.

Gutierrez, A. B. (2002): Las prácticas sociales: una introducción a Pierre Bourdieu, Madrid, Tierra de Nadie Ediciones.

Lomsacov, P. (2010): «El campo de la producción, edición y distribución de historietas realistas en Argentina entre 2003 y 2009», Estudios y Crítica de la Historieta Argentina [en línea: http://historietasargentinas.wordpress. com/2010/07/16/37-el-campo-de-la-produccion-edicion-y-distribucion-dehistorietas-realistas-en-argentina-entre-2003-y-2009-pablo-ivan-lomsacov/

Martin, A. (1978): Historia del cómic español, 1875-1939, Barcelona, Gustavo Gili.

Pilar, H. (2012): «Delirios terminales o anecdotario de historias sobre historietas», en el blog del Seminario de Sociología de la Historieta Realista, Escuela de Ciencias de la Información, Universidad Nacional de Córdoba: http://www.seminariohistorieta.blogspot.com.ar/2012/04/colaboracion-dela-companera-pilar.html

RegGiani, F. (2008): «De la revista al libro: la edición de historietas argentinas después del 2001», Estudios y Crítica de la Historieta Argentina [línea: http://historietasargentinas.wordpress.com/2008/12/09/de-la-revista-al-libro-la-edicion-de-historietas-argentinas-despues-federico-reggiani/

- (2009): «Quisiera ser literatura: el prólogo como recurso de legitimación en la edición de libros de historieta en Argentina. El caso de la Biblioteca Clarín de la Historieta», Actas del VII Congreso Internacional Orbis Tertius de Teoría y Crítica Literaria, La Plata [en línea:

http://www.orbistertius.unlp.edu.ar/congresos/viicitclot/actas-del-vii-congreso-internacional-orbis-tertius-1/ponencias/Reggiani.pdf

- (2012): «Experimentos con humanos», Cuadritos de Historietas [en línea: http://avcomics.wordpress.com/2012/02/12/11045/]

RocA, P. (2010): El invierno del dibujante, Bilbao, Astiberri.

Sasturain, J. (1995): El domicilio de la aventura, Buenos Aires, Colihue.

Sasturain, J.; C. Trillo; G. Saccomanno (1980): Historia de la historieta argentina, Buenos Aires, Ediciones Record.

VAzQuez, L. (2010): El Oficio de las Viñetas: la industria de la historieta argentina, Buenos Aires, Paidós.

Von Sprecher, R. (1998): El Eternauta: la sociedad como imposible, Córdoba, JCV Editorial. 
- (Coord.): (2007): Teorías sociológicas. Introducción a los contemporáneos, Córdoba, Editorial Brujas.

- (2009): «Desarrollo del campo de la historieta argentina: entre la dependencia y la autonomía», Quito, en revista Diálogos de la Comunicación, n. ${ }^{\circ} 78$, julio/diciembre. Felafacs, Revista de la Confederación de Facultades de Comunicación Social de América Latina. En línea: http://www.dialogosfelafacs.net/78/articulos.php

Von Sprecher, R.; J. Pestano (2010): Marco para el estudio de la historia del campo del comic. Congreso 200 años: medios, comunicación y cultura, Córdoba, Congreso Bicentenario, Escuela de Ciencias de la Información, Universidad Nacional de Córdoba.

Von Sprecher, R.; F. REgGiani (eds.): (2010): Héctor Germán Oesterheld: De El Eternauta Montoneros, Córdoba, Escuela de Ciencias de la Información, Universidad Nacional de Córdoba.

- (Eds.): (2011): Teorías sobre la historieta, Córdoba, Escuela de Ciencias de la Información, Universidad Nacional de Córdoba.

Revista Del Equipo De Investigación Estudios Y Crítica de la Historieta Argentina, Córdoba, en línea: www.historietasargentinas.wordpress.com

Weber, M. (2011): La Etica Protestante y el Espiritu del Capitalismo, edición crítica a cargo de Gil Villegas, M. (ed.), México, Fondo de Cultura Económica.

Williams, R. (1980): Marxismo y literatura, Barcelona, Ediciones Península.

- (1982): Cultura. Sociología de la comunicación y del arte, Barcelona, Paidós. 